\title{
Editorial
}

\section{The failing Economy}

While the obituary has yet to be written, it is feared that the Token Economy, as originally promulgated by Ayllon and Azrin (1968), is in poor health. It survived many legal onslaughts (Kazdin, 1977) and emerged battered and bruised, but wiser for it all. Practices yet to be empirically validated, have yet been grafted on to it (Ulmer, 1977), and despite the disfigurement, it is not known whether the graft will 'take'. It has stimulated the cognitive processes of all but a few myopic practitioners. The pendulum which swung from the extreme of self-determinism to that of environmental determinism, now serenely reposes over the concept of reciprocal determinism. The view that behaviour change involves a bi-directional process (Bandura, 1969) and the knowledge that the role of cognitive mediational events cannot be blithely disregarded (Mahoney, 1974), may bring some practitioners to the bedside--to pay their respects before leaving.

However, it's poor prognosis is felt to be related, not to the above development, but to the exploratory laparotomy currently being conducted: to identify the crucial, facilitatory and inert components, of the 'total treatment package' ordinarily used in the Token Economy. When the wound is closed and the sutures inserted, it is felt that the obituary will have to be seriously considered. Taking cognizance of the possibility that specific components of the 'total treatment package' may be differentially effective across different sets of target behaviours in any given individual, or perhaps along dimensions related to differences between individuals. it is felt that future contingency management programmes will be built around a 'social stimulation-social interaction -social reinforcement model', and that contingent token conditions, for long the overemphasized component of the Token Economy 'package', will be more than a useful adjunct, to be used only if and when necessary (Fernandez, 1974).

\section{References}

$$
\begin{array}{ll}
\text { Dr. J. Fernandez } & \text { St. Brendan's Hospital, } \\
\text { Consultant Psychiatrist } & \begin{array}{l}
\text { Dublin, Ireland }
\end{array}
\end{array}
$$

AYLLON, T., and AZRIN, N. H. (1968). The Token Economy: A Motivational System for Therapy and Rehabilitation. New York: Appleton-Century-Crofts.

BANDURA, A. (1969). Principles of Behaviour Modification. New York: Holt, Rinehart and Winston.

FERNANDEZ, J. (1974). Token economies: Is contingent token reinforcement really necessary? Paper presented at the Eighth Annual Conference of the Association for Advancement of Behaviour Therapy, Chicago.

KAZDIN, A. E. (1977). The Token Eonnomy: A Review and Evaluation. New York: Plenum Press.

MAHONEY, M. J. (1974). Cognition and Behaviour Modification. Massachusetts: Ballinger.

ULMER, R. A. (1977). On the Development of a Token Economy Mental Hospital Treatment Program. Washington D.C.: Halstead Press. 